\title{
The Left Ventricular Dysfunction Questionnaire: Italian translation and validation
}

\author{
LVD-36: traduzione italiana e validazione del test
}

\author{
Daniela Miani, ***Dario Gregori, *Marco Ghidina, *Patrizia Rozbowsky, \\ **Laura Pilotto, Maria Cecilia Albanese, Claudio Fresco, Paolo Maria Fioretti
}

\begin{abstract}
The Left Ventricular Dysfunction Questionnaire: Italian translation and validation. D. Miani, D. Gregori, M. Ghidina, P. Rozbowsky, L. Pilotto, M.C. Albanese, C. Fresco, P.M. Fioretti.

Patients affected by heart failure have a compromised quality of life (QOL) and in the last few years "health related quality of life" has become an important outcome indicator for the evaluation of heart failure treatment.

Methods: Translation into Italian of the Left Ventricular Dysfunction Questionnaire (LVD-36), a new, 36-item, disease-specific health status instrument for patients with congestive heart failure, and its subsequent validation by administration to 50 consecutive patients in our heart failure outpatient clinic. The Italian LVD-36 was compared to the "The Minnesota Living with Heart Failure Questionnaire" (MLHF).

Results: The Italian version of the LVD-36 correlates
\end{abstract}

well with MLHF for ejection fraction (EF), NYHA class I and II, etiology and therapy. Since, however, the LVD-36 has only one domain, it may be able to offer more synthetic information than MLHF about patients' status.

Conclusions: The Italian version of the LVD-36 appears to be a reliable instrument for assessing patients' QOL and the degree of limitations imposed on them by the disease. It is short, clear and easy to complete. In patients with heart failure the LVD-36 correlates well with the MLHF and may be considered a new disease- specific instrument to estimate changes in health status, and an useful support in optimizing therapeutic options.

Keywords: heart failure, left ventricular dysfunction questionnaire, minnesota living with heart failure questionnaire, instrument.

Monaldi Arch Chest Dis 2005; 64: 100-104.

Department of Cardiopulmonary Sciences. Ospedale "S. Maria Della Misericordia", Udine, Italy.

* Research Foundation IRCAB, Udine Italy.

** Consultant, Health Promotion/Health Education, Azienda per i Servizi Sanitari "Medio Friuli" Udine, Italy.

*** Department of Public Health and Microbiology, University of Torino, Italy.

In patients with congestive heart failure (CHF) measurement of health related quality of life is an important outcome indicator for evaluating the impact of the disease and treatment efficacy. It is known that patients affected by CHF have a compromised quality of life. ${ }^{1-4}$

In Italy more than 3 million people are affected by the disease in a population of 57,800,000 inhabitants. 5

Quality of life (QOL) is considered a multidimensional phenomenon, which can be analyzed from different perspectives including the physical, psychological, social and economic well being or status of patients. It can be measured by generic or disease specific questionnaires. Among the questionnaires most used to assess the QOL of CHF patients are the Minnesota Living with Heart Failure (MLHF) and the Chronic Heart Failure Questionnaire (CHFQ), both specific questionnaires, and the Short Form - 36 (SF-36) a generic questionnaire. Some problems related to these questionnaires are the length of the questionnaire, the time it takes to complete them, and the lack of sensitivity in picking up small changes in patients' health status. ${ }^{6}$

One of the newer tests currently used is the Left Ventricular Dysfunction (LVD-36) ${ }^{7}$ questionnaire, a short instrument, easy to administer and to score, but at the same time fulfilling the necessary psychome- tric requirements for health status measurement. Questionnaires usually evaluate domains that reflect a patient's cultural and ethnic background and are generally worded using idiomatic expressions typical of the respondent's own language and environment; hence it is possible that application to another culture of a questionnaire may affect the results and in particular the interpretation of the data.

Therefore, the main objective of this study was the translation into Italian and validation of the original LVD-36.

\section{Methods}

The LVD-36 questionnaire, created by O'Leary in $2000,{ }^{7}$ is a specific instrument aimed at evaluating QOL in patients with CHF. The questionnaire was originally targeted at patients suffering from left ventricular dysfunction, and subsequently extended to CHF patients. The LVD-36 is composed of 36 items with dichotomous responses (true/false). The derived overall score represents the patient's perceived global QOL.

Patients are asked to indicate if their cardiac condition affects daily life in terms of the following aspects: (i) physical, (ii) fear of being in a situation of shortness of breath, (iii) daily life activities and social interactions, (iv) feeling of being tired (v) emotional and psychological distress. 
Our linguistic adaptation of the instrument was performed according to the standardized protocol of the MAPI Research Institute (http://www.mapiresearch-inst.com/). The linguistic validation of the translation, which allows its assessment in the pertinent target countries, verifies that the translated version is conceptually equivalent to the original questionnaire, ensuring the cross-cultural equivalence across translations.

This linguistic validation follows several steps. In our process, after the production of two independent translations by two professional translators, native speakers in the target language, a professional English native translator produced the backward translation. Then the original version, the developed Italian version and the back translation were compared discussing any discrepancies with expert cardiologists and psychologists. A cognitive debriefing, consisting in interviews with the patients conducted by trained psychologists, was carried out to test the interpretability of the resulting version.

The quality control of the data collected was performed by the IRCAB Foundation.

The MLHF8 is a 21-item instrument, which uses a 6-point response scale to assess the patient's emotional and physical dimensions, and produces a general total score. Since its creation in 1987, the MLHF has become one of the most frequently used questionnaires for evaluating CHF patient's well-being. For this reason, in the validation process, the final Italian version of the LVD-36 was administered along with the MLHF and the Kansas City Cardiomyopathy Questionnaire ${ }^{9}$ to the same sample of 50 consecutive patients attending the heart failure clinic at our institution. This is a tertiary care outpatient clinic and patients come from all socioeconomic and cultural backgrounds.

\section{Statistical analysis}

Data for both the Italian LVD-36 and MLHF variables were transformed in order to obtain the same range and interpretation. 10 The scores were standardized on a scale of 0-100, 100 indicating a higher level of functioning, and the directions were redefined to guarantee a homogeneous interpretation. The scoring system is available upon request from the IRCAB Foundation (http://www.insiel.net/ircab).

Correlations between the two scales were computed using a non-parametric Spearman's Rho. Data are described as median, first and third quartile for continuous variables, and as percentages and counts for discrete variables. Spearman's correlations between LVD-36 and MLHF scores were computed for several subgroups, according to major clinical variables. Differences between the LVD-36 score and MLHF domain and total scores with respect to NYHA levels were evaluated using a K-independent samples non-parametric median test. The Spearman's correlations between each pair of MLHF and LVD-36 domains were also computed.

Significance was set at $0.01,0.05$ levels. All calculations were performed using the SPSS 7.0 statistical package.

\section{Results}

The Italian version of the LVD-36 is reported in the appendix.

Patient characteristics are presented in table 1. The study sample included 50 patients, 40 men $(80 \%)$ and 10 women $(20 \%)$, median age 63 years. Only $8 \%$ of patients were in NYHA class I, whereas 52\% were in NYHA class II (26 pts) and $40 \%$ in NYHA class III (20 pts). The median EF was $30 \%$. The etiology was ischemic in $40 \%$ of cases, dilatative in $36 \%$, and valvular in $24 \%$. The majority of patients had been hospitalized during the previous year $(77 \%)$. Ace inhibitors therapy was administered in $88 \%$ of cases and betablockers in $56 \%$.

A comparison of standardized total scores between the MLHF and Italian version of the LVD-36 is presented in table 2 .

The Italian version of the LVD-36 demonstrated clear changes in patients' QOL for the different NYHA classes. A good correlation was observed with MLHF for EF, NYHA class I and II, etiology and therapy. The correlation was lower for women, NYHA class III and patients with previous hospitalizations. The MLHF shows total score higher than LVD-36 in quantifying QOL (table 2). From table 3 it can been seen that the higher the NHYA class, the lower the score for QOL. Table 4 shows that all domains of the MLHF (emotional, physical, and overall score) correlated with the LVD-36 score.

\section{Discussion}

This study reports the translation into Italian and subsequent validation of the Left Ventricular Dysfunction Questionnaire, a disease-specific, health related QOL instrument with a well-documented validity, reliability and responsiveness ${ }^{7}$. The questionnaire quantifies the detriment in quality of life experienced by patients with left ventricular dysfunction. In the original study on the LVD-36,7 it was compared with both the SF-3611 and MLHF and similar

\begin{tabular}{lc} 
Table 1. - Patient Characteristics $(\mathrm{N}=50)$ \\
\hline Age & $63(56 ; 69)^{*}$ \\
Gender: & \\
$\quad$ Male & $80 \%(\mathrm{~N}=40)$ \\
$\quad$ Female & $20 \%(\mathrm{~N}=10)$ \\
NYHA class: & $8 \%(\mathrm{~N}=4)$ \\
I & $52 \%(\mathrm{~N}=26)$ \\
II & $40 \%(\mathrm{~N}=20)$ \\
III & $30(23 ; 35) *$ \\
Ejection Fraction & $40 \%(\mathrm{~N}=20)$ \\
Etiology: & $24 \%(\mathrm{~N}=12)$ \\
Ischemic & $36 \%(\mathrm{~N}=18)$ \\
Valvular & $77 \%(\mathrm{~N}=37)$ \\
$\quad$ Dilatative & \\
Previous hospitalizations & $88 \%(\mathrm{~N}=44)$ \\
Therapy: & $56 \%(\mathrm{~N}=28)$ \\
$\quad$ ACE inhibitors & \\
Beta blockers & \\
\hline Legend: N: number of subjects with valid data for variable. \\
* median [I quartile; III quartile].
\end{tabular}


Table 2. - Comparison of standardized total scores* between the MLHF and Italian LV D-36 questionnaires

\begin{tabular}{lrrrr}
\hline & & MLHF & Italian LVD-36 & Correlation \\
\hline Ejection Fraction & $\leq 30$ & $81(51 ; 90)$ & $56(33 ; 77)$ & 0.772 \\
NYHA class & $>30$ & $87(64 ; 91)$ & $61(33 ; 78)$ & 0.756 \\
& I-II & $90(70 ; 92)$ & $68(43 ; 78)$ & 0.763 \\
Etiology & III & $73(47 ; 81)$ & $45(27 ; 60)$ & 0.544 \\
& Ischemic & $84(60 ; 90)$ & $56(32 ; 76)$ & 0.898 \\
Gender & Valvular & $82(43 ; 92)$ & $60(36 ; 80)$ & 0.606 \\
& Dilatative & $85(60 ; 90)$ & $61(36 ; 78)$ & 0.754 \\
ACE inhibitors & Male & $82(48 ; 90)$ & $57(31 ; 79)$ & 0.572 \\
Beta blockers & Female & $87(78 ; 92)$ & $58(53 ; 72)$ & 0.717 \\
& Yes & $87(64 ; 91)$ & $60(38 ; 78)$ & 0.771 \\
Previous hospitalizations & No & $38(31 ; 78)$ & $25(14 ; 61)$ & 0.754 \\
Yes & $87(60 ; 90)$ & $50(22 ; 79)$ & 0.777 \\
Overall & No & $81(47 ; 91)$ & $64(40 ; 91)$ & 0.782 \\
\hline
\end{tabular}

Legend: MLHF: Minnesota Living with Heart Failure; LVD-36: Left Ventricular Dysfunction Questionnaire.

*median [I quartile; III quartile].

Table 3. - Comparison of standardized total scores* by NYHA class between the MLHF and Italian LVD-36 questionnaires

\begin{tabular}{|c|c|c|c|c|}
\hline & NYHA I-II (N=30) & NYHA III (N=19) & Overall $(\mathrm{N}=49)$ & P-value \\
\hline \multicolumn{5}{|l|}{ Minnesota Living with Heart Failure } \\
\hline Minnesota Emotional Score & $92(72 ; 100)$ & $76(68 ; 92)$ & $88(72 ; 96)$ & 0.037 \\
\hline Minnesota Physical Score & $92(70 ; 97)$ & $67(35 ; 75)$ & $82(47 ; 95)$ & 0.004 \\
\hline Minnesota Total Score & $90(70 ; 92)$ & $73(47 ; 81)$ & $85(51 ; 90)$ & $<0.001$ \\
\hline \multicolumn{5}{|c|}{ Left Ventricular Dysfunction Questionnaire } \\
\hline Left Ventricular Dysfunction Score & $68(43 ; 78)$ & $45(27 ; 60)$ & $57(33 ; 78)$ & 0.004 \\
\hline
\end{tabular}

Table 4. - Correlation between domain and total scores of the MLHF and the Italian LVD-36 (single domain)

\begin{tabular}{lcc}
\hline & \multicolumn{2}{c}{ Minnesota Living with Heart Failure } \\
\cline { 2 - 3 } & $0.509^{*}$ & $0.566^{*}$ \\
Italian LVD-36 Score & $0.606^{*}$ \\
\hline $\begin{array}{l}\text { MLHF: Minnesota Living with Heart Failure; LVD-36: Left Ventricular Dysfunction Questionnaire. } \\
\text { Correlation is significant at the .01 level (1-tailed). }\end{array}$
\end{tabular}

correlations were found, although there was a slightly higher correlation with SF-36. According to O'Leary and Jones, the LVD-36 provided a more precise and sensitive estimate of changes in health status than the existing questionnaires. Other authors have found that the MLHF's ability to differentiate symptom severity is good except in the most compromised patients. 12

The lower correlation between the MLHF and Italian version of the LVD-36 that we found for women is probably due to the fact that women gen- erally have a poorer QOL than men, as reflected in the literature.13,14 Our study also showed that the more compromised the patient, such as those in NYHA class III, the lower the correlation between the two instruments; the correlation is lower also for patients who have had more than one hospitalization in the previous year. As stated before, the Italian version of the LVD-36 correlates well with MLHF for all domains. The two questionnaires also correlated well for EF, NYHA class, etiology, and therapy. The LVD-36 has less domains than the 
MLHF, but it is short and simple to complete and easy to score. However a test that contains true and false responses does not allow clinicians to detect the small changes important in heart failure management. Moreover a single total score cannot identify the source of quality of life impairment or improvement with regard to functional or emotional domains.

Limitations of our study are the low number of patients enrolled, and the fact that none were in NYHA IV class, since all were outpatients, had stable symptoms and were self-sufficient and living in the community. Another important difference between the two questionnaires is their reference time frame. The LVD-36, in fact, asks about the patient's status in "these days" whereas the MLHF is based on a one-month span. This period is longer than some authors have recommended 15 ; it has been pointed out that asking about the last few days is better than asking about the past few weeks.

In conclusion, the Italian version of LVD-36 appears to be a valid instrument for assessing a patient's QOL and the degree of limitations imposed by the disease, because it correlates well with the MLHF that currently represents the gold standard for patients with heart failure. In the original study carried out on the LVD-36, the LVD-36 administered repeatedly to the same patients was found to be somewhat more informative about clinical changes than the MLHF, quick, easy to perform and it tended to be more responsive. This capacity may represent an advantage of the LVD-36, with respect to the MLHF, in detecting clinical changes and supporting subsequent therapeutic options.

\section{Riassunto}

Background: I pazienti affetti da scompenso cardiaco hanno una qualità di vita compromessa. Negli ultimi anni l'analisi della qualità della vita è diventata un importante indicatore sugli interventi e sul trattamento dello scompenso cardiaco.

Metodi: Traduzione in lingua italiana e validazione linguistica del Left Ventricular Dysfunction Questionnaire (LVD-36), strumento specifico composto da 36 items per pazienti affetti da scompenso cardiaco.

La validazione è stata eseguita somministrandolo a 50 pazienti consecutivi appartenenti all' ambulatorio dello scompenso cardiaco.

L'LVD-36 è stato comparato al Minnesota Living with Heart Failure Questionnaire (MLHF).

Risultati: La versione italiana del LVD-36 correla bene con il MLHF per la frazione di eiezione $(E F)$, la classe NYHA I-II per l' eziologia e la terapia, tuttavia l' $L V D-36$, poiché cont iene un solo dominio, da un'informazione più sintetica sullo stato del paziente.

Conclusioni: LVD-36 nella sua versione italiana, appare essere uno strumento valido per valutare la qualità della vita ed il grado di limitazioni imposte dalla malattia. È breve, chiaro e facile da completare. L'LVD-36 correla bene con il MLHF e deve essere preso in considerazione come nuovo strumento specifico per valutare i cambiamenti del- lo stato di salute dei pazienti con scompenso cardiaco ed essere utile per ottimizzare le opzioni terapeutiche.

\section{List of acronyms and abbreviations}

QOL: quality of life

LVD-36: Left Ventricular Dysfunction Questionnaire

MLHF: Minnesota Living with Heart Failure Questionnaire EF: ejection fraction

NYHA: New York Heart Association

CHF: congestive heart failure

\section{References}

1. Andresen EM, Meyers AR. Health-related quality of life outcomes measures. Arch Phys Med Rehabil 2000; 81 (Suppl 12): S30-S45.

2. Dracup K, Walden JA, Stevenson LW, Brecht ML. Quality of life in patients with advanced heart failure. J Heart Lung Transplant 1992; 11: 273-279.

3. Gorkin L, Norvell NK, Rosen RC. Assessment of quality of life as observed from baseline data of the Studies of Left Ventricular Dysfunction (SOLVD-36) trial quality of life sub-study. Am J Cardiol 1993; 71: 1069-1073.

4. Konstam MA, Salem D, Pouleur H, et al. Baseline quality of life as a predictor of mortality and hospitalization in 5025 patients with congestive heart failure. Am J Cardiol 1996; 78: 890-895.

5. Rengo F, Leosco D, Iacovoni A, et al. Epidemiologia clinica e fattori di rischio per scompenso cardiaco nell'anziano. Ital Heart J 2004; 5 (suppl. 10): 9S-16S.

6. Rector TS, Johnson G, Rector, et al. Evaluation by patients with heart failure of the effects of enalapril compared with hydralazine plus isosorbide dinitrate on quality of life. Circulation 1993; 87 (suppl VI): 71-7.

7. O'Leary CJ, Jones PW. The left ventricular dysfunction questionnaire (LVD-36-36): reliability, validity, and responsiveness. Heart 2000 Jun; 83 (6): 634-40.

8. Rector T, Kubo S, Cohn J. Patient's self-assessment of their congestive heart failure. Part 2: content, reliability and validity of a new measure, the Minnesota Living with Heart Failure Questionnaire. Heart Failure 1987; 3: 198209.

9. Miani D, Rozbowsky P, Gregori D, et al. The Kansas City Cardiomyopathy Questionnaire: Italian translation and validation. Ital Heart J 2003; 4 (9): 620-626.

10. Bouchet C, Guillemin F, Paul-Dauphin A, Briancon S. Selection of quality of life measures for a prevention trial. A psychometric analysis. Control Clin Trials 2000; 21: 30-43.

11. McHorney C, Ware J, Raczek A. The MOS-Item ShortForm Health Survey (SF-36): II. Psychometric and clinical tests of validity in measuring physical and mental health constructs. Med Care 1993; 31: 247-63.

12. Riegel B, Moser DK, Glaser D, et al. The Minnesota Living with Heart Failure Questionnaire. Sensitivity to differences and responsiveness to intervention intensity and clinical population. Nursing Research 2002; 51: 209-218.

13. Riedinger MS, Dracup KA, Brecht ML, Padilla G, Sarna L for the SOLVD-36 Investigators, and Ganz PA. Quality of life in patients with heart failure: do gender differences exist? Heart Lung 2001; 30: 105-116.

14. Riegel B, Moser DK, Carlson B et al. Gender differences in quality of life are minimal in patients with heart failure. J Card Fail 2003; 9: 42-48.

15. Osoba D. Guidelines for measuring Health-Related Quality of Life in clinical trials. In: Staquet MJ, Hays RD, Fayers PM, Editors. Quality of life assessment in clinical trials. Oxford: Oxford University Press; 1998: 56-7. 


\section{Appendix}

La preghiamo di rispondere alle seguenti domande a seconda di come si sente in questi giorni.

Segni con una crocetta vero o falso per ogni domanda.

A causa della mia condizione cardiaca:

1. Soffro di affaticamento alle gambe

2. Soffro di nausea (mi sento male)

3. Soffro di gonfiore alle gambe...

22. Ml sento frustrato

23. Mi sento nervoso.

24. Mi sento irritabile

25. Mi sento affaticato

A causa della mia condizione cardiaca:

26. Ml sento di aver perso il controllo della mia vita....

27. Sento di non poter godere appieno della mia vita

4. Ho paura che quando esco mi possa mancare il fiato

5. Evito di affaticarmi per paura che mi manchi il respiro.

6. Mi manca il fiato con il minimo sforzo

7. Ho paura di esagerare (sforzarmi troppo)

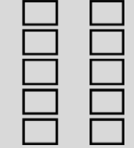

8. Impiego molto tempo a lavarmi e vestirmi

28. Ho perso sicurezza in me stesso

\section{A causa della mia condizione cardiaca:}

A causa della mia condizione cardiaca /se non fate queste attivita' per qualsiasi ragione che non sia la vostra condizione cardiaca, allora barrate la risposta falso"'

29. Ho difficoltà ad avere una vita sociale regolare.

30. Ci sono posti che vorrei visitare ma non posso

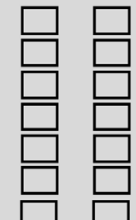

31. Ho paura che andando in vacanza la mia condizione cardiaca possa peggiorare..

9. Ho difficoltà a correre, per esempio per prendere l'autobus....

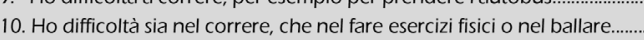

11. Ho difficoltà a giocare con i bambini/nipoti...

12. Ho difficoltả a tagliare l'erba del giardino o passare l'aspirapolvere.......

32. Ho dovuto modificare il mio stile di vita

33. Sono limitato nell'adempimento dei miei obblighi familiari............................

34. Mi sento di dipendere dagli altri

\section{A causa della mia condizione cardiaca:}

13. Mi sento sfinito

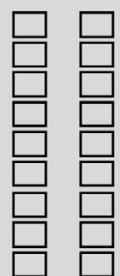

\section{A causa della mia condizione cardiaca:}

35. Trovo veramante seccante dover prendere i medicinali per i miei problemi cardiaci.

14. Mi sento privo di energie

15. Mi sento assonnato

La mia condizione cardiaca mi impedisce di fare quello

.

17. Mi sembra che ogni cosa da fare sia uno sforzo

18. Sento la mia muscolatura debole

19. Sento freddo facilmente.

20. Mi sveglio spesso durante la notte

21. Sono diventato fragile o mi sento invalidato

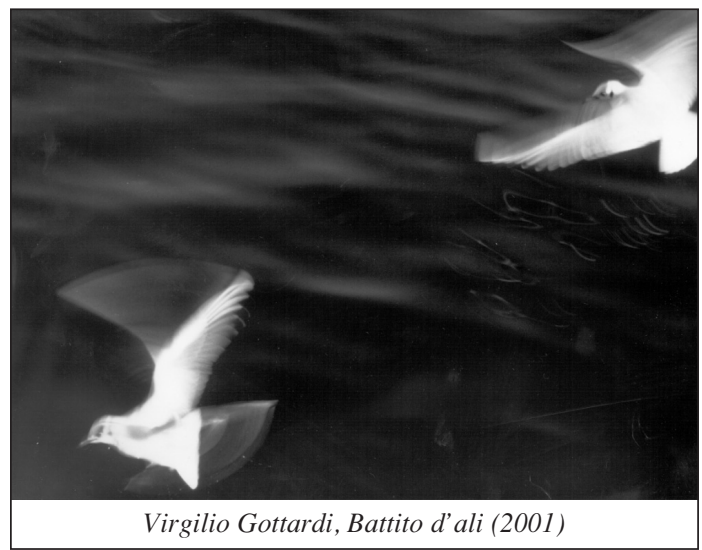

